\title{
EMPLOYMENT STATUS, JOB TYPE AND EMPLOYER DESCRIPTION AMONG PERSONS WITH A SIGNIFICANT VISUAL IMPAIRMENT IN NEW ZEALAND
}

\author{
Steven J La Grow \\ School of Health Sciences \\ Massey University
}

\begin{abstract}
A random sample of 150 working aged members of the Royal New Zealand Foundation of the Blind were canvassed about their employment status, the sector in which they were employed and the types of jobs they held. It was found that although $39 \%$ were currently in paid employment, $64 \%$ indicated that they 'mostly have had paid employment' or had 'always had paid employment' since reaching working age. When asked about the position they currently held, $46 \%$ said they worked in the private sector, $24 \%$ said they were employed in the public sector, and $25 \%$ said they were selfemployed; $5 \%$ responded as 'other'. In terms of the types of jobs they were in, $29 \%$ percent said they were in either sales or service, $23 \%$ in professional or managerial positions, $13 \%$ in clerical positions, $14 \%$ in unskilled labour. $8 \%$ in skilled labour, $2 \%$ in technical jobs; $14 \%$ responded as 'other'. When asked to rate their current position in terms of their skills or abilities, 30\% rated it as either 'way too low', or as 'a bit too low; while, $70 \%$ rated as about right. A number of demographic variables were investigated to see if they had an affect on the positions held.
\end{abstract}

\section{Introduction}

Rates of employment are generally low among persons with a severe visual disability world-wide (Wolffe \& Spungin, 2002). Even in the most developed countries they are employed at about half the rate enjoyed by the rest of the population (McNeil, 2001; Tillsley, 1997). The employment rate for people with a vision impairment in the United States, for example, was reported to be $42.2 \%$ in $1996 / 97$ by the US Bureau of the Census. This compares to $78.2 \%$ for the general population for the same time period. This rate is a bit better than half the rate of the general population. Yet, when broken down by severity, those with a 'severe' vision problem had an employment rate of just $30 \%$ compared to $44.1 \%$ for those whose problem was deemed to be 'not severe' (McNeil, 2000). Thus, those with the most severe visual impairment had an employment rate of just under $40 \%$ of that of the general population.

Barriers to employment for this population are varied, and include numerous references to the limitations imposed by the vision impairment itself, the cost and accessibility of adaptive equipment and/or the availability of training to deal with those limitations, and accessibility to the environment in general. However, employer ignorance and prejudice is consistently identified as one of the major barriers visually impaired people face when seeking employment (Crudden, 2002; Hagemoser, 1996; Malakpa, 1994; O’Day, 1999; Rumrill, Schuyler \& Longden, 1997; Salomone \& Paige, 1984; Tillsley, 1997; Wolffe \& Spungin, 2002). Employers often assume a person with a vision impairment, especially a severe visual impairment such as total blindness, simply could not do their job, or do it safely. This assumption, however, is typically based on little information other than their assumption that if they could not see, they could not perform the job themselves. Yet, these people are certainly not unemployable, as an employment rte of $30 \%$ would suggest, and in fact they successfully fill numerous jobs right across the occupational spectrum.

In order to identify the types and range of jobs that visually impaired people do hold the World Blind Union's (WBU) Committee on Rehabilitation and Employment surveyed 102 WBU member organizations in 75 countries to determine the types of jobs performed by visually impaired adults throughout the world (Wolffe \& Spungin, 2002). The questions asked were open ended. Over 100 types of jobs were identified and clustered into 8 occupational categories. These categories were (a) executive, administrative, and managerial; (b) professional specialty; (c) technician and related support; (d) marketing and sales; (e) administrative support, including clerical service; (f) agricultural, forestry, fishing, and related jobs; $(\mathrm{g})$ precision production, craft and repair; and (h) operators, fabricators, and laborers (Wolffe \& Spungin, 2002).

Level of education made the most difference in the types of jobs people had. Those with less than 8 years of formal education worked as operators, fabricators, and laborers, while those with more than 8 years of education were mostly in professional or speciality occupations, followed by administrative support, including clerical work. There was little difference noted in the types of jobs people held based on severity of visual impairment (Wolffe \& Spungin, 2002).

Little information is available on the employment status of visually impaired persons in New Zealand. This study was conducted to determine the employment status of a sample of visually impaired people in New Zealand, to identify their rates of employment, the types of jobs they 
hold and the sector in which they are most commonly employed.

\section{Method}

Participants were randomly selected for this study by calling every fifth name on list of members of the Royal New Zealand Foundation of the Blind between the ages of 18 and 64 until 150 had agreed to participate (See La Grow, 2003). Members were called and informed of the purpose of the study and their right to decline to participate if they so wished. Those who agreed to participate were asked a series of questions concerning their employment status, employment history, the type of job they held and the sector in which they were employed for both their current and previous job. They were informed that they could choose to decline to answer any question or to withdraw from participation at any time. All participants were asked about their employment status and for demographic details. Only those who were considered to be in the labour force (i.e. in employment or interested in gaining employment) were asked further questions concerning their level of employment and employment history.

Of the 150 members who agreed to participate in this study, $45 \%$ were male $(n=67)$ and $55 \%$ female $(n=83)$. They ranged in age from 18 to 64 with a mean age of 43 . When asked about ethnicity, $79 \%$ identified themselves as NZ European $(n=117), 10 \%$ as NZ Maori $(n=15)$, $4 \%$ as Pacific People $(n=6)$ and $7 \%$ as 'other' $(n=11)$. One did not respond to this question. The ethnic distribution of the participants in this study did not differ greatly from the New Zealand population as whole. In the 1986 census for example, $81 \%$ of the population indicated that they belonged to an ethnic group other than NZ Maori or Pacific People, 14\% identified themselves as NZ Maori and $5 \%$ as Pacific People (Statistics New Zealand, 1998).

\section{Employment Status}

When asked about their employment status, 59 of the participants stated that they were currently in paid employment (39.3\%), 36 were interested in employment but not employed $(24 \%)$, and $55(36.6 \%)$ were neither employed nor interested in gaining employment. Of those interested in paid employment, 21 were currently seeking employment and 15 were not. This compares to an overall employment rate of $70 \%$ for New Zealand in 2001 (Statistics New Zealand, 2003). When divided by amount of vision, it was found that $26 \%$ of those with no usable vision (totally blind) were employed as compared to $47 \%$ of those with 'a little' or 'a lot' (not totally blind). These figures are not dissimilar to those reported by the US Bureau of the Census (McNeil, 2000). They, however, may not be directly comparable due to differences in definition used to identify the population across the countries.

In this study, participants were separated according to amount of useful vision they reported as having. $26 \%$ of those with 'no' useful vision were in paid employment, as compared to $35 \%$ of those with 'a little' and $63 \%$ of those who stated they had 'a lot'. The differences across these groups (Pearson Chi-Square $=10.76$ ) were statistically significant $(p=.005)$, with those with the least amount of vision being less likely to be in paid employment than those with 'a little' or 'a lot'. However, this was also affected by gender. Of the 13 males with no usable vision $38 \%$ were in paid employment, of the 38 with 'a little' vision $39 \%$ were, and of the 15 with 'a lot' of vision $60 \%$ were. For the woman however, only $14 \%$ of the 14 women with no usable vision were in paid employment, while $32 \%$ of the 50 with a little vision were, and $66 \%$ of the 18 with a lot were. Thus, the difference in percentage in employment between males and females in relation to degree of vision (Chi-Square $=$ 10.47) was also significant $(p=.005)$.

Of those in paid employment, $47.5 \%$ worked less than 31 hours per week, $23.7 \%$ worked from 31 to 40 hours and $11.3 \%$ worked more than forty hours per week. Thus, at least $47.5 \%$ would be considered in part-time employment. $23.7 \%$ stated that the number of hours they worked was way too few or a bit too few, $67.8 \%$ said it was a bout right or a bit too many, and $8.5 \%$ said it was way too many.

60 of the $150(40 \%)$ served as volunteers in the community, $50 \%$ of those were also in paid employment, while $50 \%$ were not. Of those not seeking employment, 21 were in continuing education. Seven of those stated that they would accept employment if it were available, 14 said they would not.

\section{Employment Type}

When asked to identify the type of job currently held, 9 of the $52(17.3 \%)$, who answered this question (i.e., only those who were currently employed were asked to respond to this question) identified it as service related. Six $(11.5 \%)$ could be considered to be in executive, administrative or managerial positions, $6(11.5 \%)$ in the professional or specialty category, $1(2 \%)$ as a technician, $6(11.5 \%)$ in marketing and sales, $6(11.5 \%)$ as clerical, 4 $(7.7 \%)$ as skilled labourers and $7(13.5 \%)$ as unskilled labourers. A further $7(13.5 \%)$ identified their position as 'other'. These categories relate closely to those identified by Wolffe and Spungin (2002) and reflect the same range in occupation and job type they reported. While they did not identify 'service' as a separate category, we failed to identify the category of agriculture, forestry or fishing, which it is quite possible that a number of the 7 who identified their occupational type as 'other' may have fit into.

When those who were currently employed were asked about the sector of the economy in which they worked, 27 of the 52 who responded stated that they worked in the private sector $(45.8 \%), 14$ in the public sector $(23.7 \%)$, 15 were self-employed $(28.8 \%)$, and 3 indicated the status of their employer as 'other' $(5.7 \%)$.

When all those who were in the labour force were asked to identify their last employer, 50 of the 82 who 


\begin{tabular}{|lcc|}
\hline & N & Valid Percent \\
\hline Employment Status & 5 & \\
Employed & 59 & $39.3 \%$ \\
Unemployed & 36 & $24.0 \%$ \\
In labour Market & 95 & $63.3 \%$ \\
Not in labour Market & 55 & $36.7 \%$ \\
Total & 150 & \\
Hours Employed & & \\
<30 hours per week & 28 & $47.5 \%$ \\
31 to 40 hours per week & 14 & $23.7 \%$ \\
>40 hours per week & 17 & $11.3 \%$ \\
Total & 59 & \\
Number of hours worked per week & & \\
Way or a bit too few & 14 & $23.7 \%$ \\
About right or a bit too many & 40 & $67.8 \%$ \\
Way too many & 5 & $8.5 \%$ \\
Total & 59 & \\
Type of Job Held & & \\
Service & 9 & $17.3 \%$ \\
Executive, administrative, managerial & 6 & $11.5 \%$ \\
Professional or specialist & 6 & $11.5 \%$ \\
Technician & 1 & $2.0 \%$ \\
Marketing and sales & 6 & $11.5 \%$ \\
Clerical & 6 & $11.5 \%$ \\
Skilled labour & 4 & $7.7 \%$ \\
Unskilled labour & 7 & $13.5 \%$ \\
Other & 7 & $13.5 \%$ \\
Total & 52 & \\
Employment Sector & & \\
Private & 27 & $45.8 \%$ \\
Public & 14 & $23.7 \%$ \\
Self-employed & 15 & $28.8 \%$ \\
Other & 3 & $3.7 \%$ \\
Total & 59 & \\
\hline
\end{tabular}

responded $(61 \%)$ stated that they had worked in the private sector, $22(26.8 \% \%)$ in the public sector, $7(8.5 \%)$ were self employed, and $3(3.7 \%)$ responded as other.

65 of the $94(69 \%)$ participants who responded to the question on their employment history, stated that they had always or mostly been in paid employment, while 27 $(28.7 \%)$ stated that they had mostly not been in paid employment, and $2(2.1 \%)$ stated that they had never been in paid employment. Those who were currently employed had been in their job on the average of 6.5 years, their past job for 7.2 years, and if there had been a break between jobs that break lasted for an average of 5.2 years.

\section{Level of Education}

Level of education had no significant effect on rate of employment However, $100 \%$ of those in professional, managerial, sales and clerical positions were found to have some formal educational qualification (including $6^{\text {th }}$ form certificate), while about $30 \%$ of those in the other categories did not.

\section{Conclusion}

The employment status of visually impaired persons appears to be similar to that found in the rest of the world. They are indeed employed at only about half the rate of the population in general, especially when those with the least amount of vision is concerned. A number are in part time employment, but most said that the amount they worked was about right, with about a quarter saying they worked a bit too few or way too few hours. The difference in employment rate among those with the least amount of vision and those with more is about the same as that reported in the US census. There was a significant difference in the rate employment based on degree of vision and gender with women with the least amount of vision being the least likely to be employed and those with the most vision being the most likely. The spread of jobs held is similar to that reported by Wolffe and Spungin (2000) with persons being represented in most types of jobs. The majority worked either in the private sector or were self-employed. The spread across categories of jobs was quite even. More than two thirds of those who were in the labour force stated that they 
always or mostly been in paid employment. The number $(n=36)$ who were not working but wished to be $(24 \%)$ was very high compared to this countries current unemployment rate (less than $5 \%$ ), as was the official unemployment rate $(14 \%)$ found for this group which only considers those who are actively seeking employment at the time when the question was posed $(\mathrm{n}=$ 21).

One could conclude that persons with vision impairments in this country are very interested in working and when given the opportunity, they can in fact successfully fill most types of job and be employed in all sectors of the economy.

\section{References}

Crudden, A. (2002). Employment after vision loss: Results of a collective case study. Journal of Visual Impairment and Blindness, 96, 615-621.

Hagemoser, S. (1996). The relationship of personality traits to the employment status of persons who are blind. Journal of Visual Impairment and Blindness, 90, 134-144.

Malakpa, S. (1994). Job placement of blind and visually impaired people with additional disabilities. RE:view, 26. 69-77.

McNeil, J. (2000). Employment, earnings and disability: 1991/92, 1993/94, 1994/95 and 1997 data from the Survey of Income and Program Participation. Paper presented at the $75^{\text {th }}$ Annual Conference of the Western Economic Association International. Vancouver, British Columbia, 29 June 2000.
Mc Neil, J. (2001). Americans with disabilities: 1997: Current Population Reports (Series p-70, No 73), Washington DC: U.S. Government Printing Office.

O'Day, B. (1999). Employment barriers for people with visual impairments. Journal of Visual Impairment and Blindness, 93. 627-642.

Rumrill, Schuyler, B. \& Longden, J. (1997). Profiles of on-the-job accommodations needed by professional employees who are blind. Journal of Visual Impairment and Blindness, 91, 66-76.

Salomone, P. \& Paige, R. (1984). Employment problems and solutions: Perceptions of blind and visually impaired adults. Vocational Evaluation and Work Adjustment Bulletin, 23, 55-59.

Statistics New Zealand, (2002). Disability counts. Wellington: Author.

Tillsley, C. (1997). Gaining access to employment opportunities. The British Journal of Visual Impairment, 15, 67-71.

Wolffe, K \& Spungin, S. (2002). A glance at worldwide employment of people with visual impairments. Journal of Visual Impairment and Blindness, 96. 245-254. 